\title{
Risk factors for brain metastases in completely resected small cell lung cancer: a retrospective study to identify patients most likely to benefit from prophylactic cranial irradiation
}

Hui Zhu ${ }^{1+}$, Yongmin $\mathrm{Bi}^{2+}$, Anqin Han ${ }^{1}$, Jingyu Luo ${ }^{3}$, Minghuan $\mathrm{Li}^{1}$, Fang Shi ${ }^{1}$, Li Kong ${ }^{1 *}$ and Jinming $\mathrm{Yu}^{1 *}$

\begin{abstract}
Background: The role of prophylactic cranial irradiation (PCI) on small cell lung cancer (SCLC) has been established based on the two-stage system of limited versus extensive disease and the treatment modality of chemoradiotherapy. However, the use of $\mathrm{PCl}$ after combined-modality treatment with surgery for resectable limited-stage SCLC has not been investigated sufficiently. We conducted a retrospective study to evaluate risk factors for brain metastasis (BM) in patients with surgically resected SCLC to identify those most likely to benefit from $\mathrm{PCl}$.

Patients and methods: The records of 126 patients with completely resected SCLC and definitive TNM stage based on histological examination between 2003 and 2009 were reviewed. The cumulative incidence of BM was estimated using the Kaplan-Meier method and differences between the groups were analyzed using the log-rank test. Multivariate Cox regression analysis was applied to assess the risk factors of BM.

Results: Twenty-eight patients (22.2\%) developed BM at some point during their clinical course. The actuarial risk of developing BM at 3 years was $9.7 \%$ in patients with p-stage I disease, $18.5 \%$ in patients with p-stage II disease, and $35.4 \%$ in patients with $p$-stage III disease $(p=0.013)$. The actuarial risk of developing BM at 3 years in patients with LVI was $39.9 \%$ compared to $17.5 \%$ in patients without LVI $(p=0.003)$. Multivariate analysis identified pathologic stage (hazard ratio $[H R]=2.013, p=0.017)$ and $L V I(H R=1.924, p=0.039)$ as independent factors related to increased risk of developing BM.
\end{abstract}

Conclusion: Patients with completely resected p-stage II-III SCLC and LVI are at the highest risk for BM.

Keywords: Small cell lung cancer, Brain metastases, Prophylactic cranial irradiation, Risk factors, Lymphovascular invasion, Pathologic stage

\section{Background}

Small cell lung cancer (SCLC) accounts for approximately $15 \%-20 \%$ of all lung cancers [1]. It is characterized by a high incidence of metastatic disease at presentation, rapid doubling time, and a high response rate to treatment [2]. Despite a high response to chemotherapy (ChT) and radiation therapy, most patients suffer from local recurrence or/and distant metastasis within 2 years. Brain metastases

\footnotetext{
*Correspondence: kongli7@sina.com; sdyujinming@163.com

${ }^{\dagger}$ Equal contributors

'Department of Radiation Oncology, Shandong Cancer Hospital and Institute, Shandong University, Jiyan Rd. 440, Jinan 250117, Shandong Province, China Full list of author information is available at the end of the article
}

(BM) are the most common site of distant failure in patients with SCLC, regardless of disease stage at presentation. The prevalence of $\mathrm{BM}$ detected at the time of diagnosis ranges from $10 \%$ to $24 \%$ and the probability of developing BM during the course of disease increases to $50 \%$ by 2 years after diagnosis. BM is associated with a poor prognosis and the median survival after the development of BM is only 4-6 months [3-5].

The survival advantage conferred by prophylactic cranial irradiation (PCI) in patients with SCLC has been established in recent studies. As a result, PCI has become part of the standard treatment modality for patients with SCLC who had stable disease or a better response to ChT, 
with or without thoracic radiation therapy (TRT) [6-9]. The positive role of PCI on patients with SCLC was based on the two-stage system and treatment modalities of nonsurgery. But the incidence of brain metastases in surgically treated SCLC and the risk factors for developing BM in this subgroup were rarely evaluated.

We reviewed the patients with completely resected SCLC and assessed the possible risk factors for developing $\mathrm{BM}$ in this patient population.

\section{Patients and materials}

\section{Study population}

We retrospectively reviewed the records of patients with completely resected SCLC and definitive TNM stage on the basis of histological examination at the Shandong Cancer Hospital and Institute between January 2003 and December 2009. All patients underwent a standardized evaluation, including thoracic and abdominal computed tomography scanning or abdominal ultrasonography, brain magnetic resonance imaging, and bone radionuclide imaging before surgery. All patients had negative brain computed tomography (CT) scan or magnetic resonance imaging (MRI) preoperatively and PCI was not conducted to them postoperatively. During this period, 211 patients with SCLC were operated in our cancer center, and 18 patients of them who had R1, R2 resections were excluded in this study in order to avoid bias of the results, sixty-seven patients were given PCI, so a total of 126 patients met the criteria. The study was approved by the institutional review board and ethics committee at the Shandong Cancer Hospital and Institute.

\section{Treatment}

Surgical procedures included lobectomy or pneumonectomy with ipsilateral hilar and mediastinal lymphadenectomy. Patients received either cisplatin and etoposide (PE: $30 \mathrm{mg} / \mathrm{m}^{2}$ cisplatin on days $1-3$ and either $100 \mathrm{mg} / \mathrm{m}^{2}$ etoposide on days $1-5$ or $100 \mathrm{mg} / \mathrm{m}^{2}$ etoposide on days $1-3)$ or carboplatin and etoposide (CE: carboplatin AUC 5 or $300 \mathrm{mg} / \mathrm{m}^{2}$ on day 1 and either $100 \mathrm{mg} / \mathrm{m}^{2}$ etoposide on days $1-5$ or etoposide $100 \mathrm{mg} / \mathrm{m}^{2}$ on days $1-3$ ). In our center, postoperative radiotherapy (PORT) was usually conducted to patients with lymph node metastasis. In this series, 55 patients were given PORT, 49 patients of them were staged as $\mathrm{N} 2$ and the remaining 6 patients were staged as N1. The reasons of patients with lymph node metastasis not accept PORT were as follows: patients refusal, poor lung function or low Karnofsky performance status (KPS) after surgery. Chemotherapy and radiotherapy after surgery were given sequentially to 43 patients and concurrently to 12 patients. TRT was administered by three-dimensional conformal radiotherapy technique. The clinical target volume (CTV) included the bronchial stump, ipsilateral hilum, and adjacent mediastinal lymph nodes, and the planning target volume included the CTV with a $1-\mathrm{cm}$ margin. Radiation was delivered with megavoltage linear accelerators. A total dose of 50-60 Gy was administered with 1.8-2 Gy per fraction for 5 days a week.

\section{Statistical analysis}

Overall survival (OS) was measured from the date of surgery to the date of death from any cause or the last known date that the patient was alive. Time to event of $\mathrm{BM}$ was monitored from the date of surgery to the date of $\mathrm{BM}$ or to the date of last follow-up if no BM occurred. The actuarial risk of developing BM and survival were estimated by the Kaplan-Meier method. The logrank test was used to compare the difference between groups. Multivariate analyses for BM and OS were performed using Cox regression and a backward-forward stepwise method was selected. Two-sided $p$ values $<0.05$ were considered statistically significant.

\section{Results}

\section{Patient characteristics}

Records of 126 patients were included and analyzed in this study. Patient characteristics are summarized in Table 1. The median follow-up period for all patients was 56.0 months (range, 30.4-96.8 months). The median age was 55 years (range, $34-74$ years).

\section{Factors predictive of the OS}

Median survival time for this patient population was 48.0 months. The OS rates at 2 years and 5 years were $63.2 \%$ and $47.8 \%$, respectively (Figure 1). The clinical and pathological factors evaluated to determine their prognostic value for OS are summarized in Table 2. Univariate analysis revealed that pathologic(p) -stage and development of BM were significant factors that correlated with survival rate. The 2-year and 5-year survival rates were $87.1 \%$ and $74.4 \%$, respectively, for patients with p-stage I disease; $78.6 \%$ and $61.7 \%$, respectively, for patients with p-stage II disease; and $42.6 \%$ and $26.6 \%$, respectively, for patients with p-stage III disease $(p=0.001$; Figure 2). Additionally, survival was significantly longer in the patients who did not develop BM than in patients who developed BM, with a 2-year and 5-year OS of $69.0 \%$ and $56.2 \%$ versus $42.9 \%$ and $15.5 \%$, respectively $(p=0.001$; Figure 3). Multivariate analysis revealed that age $\geq 65$ years (hazard ratio $[\mathrm{HR}]=1.798, p=0.040$ ), pathologic stage $(\mathrm{HR}=2.093, p=0.001)$, and developing $\mathrm{BM}(\mathrm{HR}=2.092, p=0.031)$ were independent prognostic factors for OS.

\section{Factors predictive of BM}

Twenty-eight patients (28/126, 22.2\%) developed BM. The time for development of $\mathrm{BM}$ ranged from 1.3 months to 
Table 1 Clinical features of patients with resectable SCLC

\begin{tabular}{|c|c|c|}
\hline Characteristic & No. & $\%$ \\
\hline \multicolumn{3}{|l|}{ Gender } \\
\hline Male & 101 & 80.2 \\
\hline Female & 25 & 19.8 \\
\hline \multicolumn{3}{|l|}{ Age (years) } \\
\hline Range & \multicolumn{2}{|c|}{$37-74$} \\
\hline Median & \multicolumn{2}{|c|}{55} \\
\hline$<65$ & 91 & 72.2 \\
\hline$\geq 65$ & 35 & 27.8 \\
\hline \multicolumn{3}{|l|}{ KPS score } \\
\hline$\geq 80$ & 80 & 64.0 \\
\hline$<80$ & 46 & 36.0 \\
\hline \multicolumn{3}{|l|}{ Smoking status } \\
\hline Yes & 72 & 57.1 \\
\hline No & 54 & 42.9 \\
\hline \multicolumn{3}{|l|}{ P-stage } \\
\hline । & 32 & 25.4 \\
\hline$\|$ & 33 & 26.2 \\
\hline III & 61 & 48.4 \\
\hline \multicolumn{3}{|l|}{ LVI } \\
\hline Yes & 30 & 23.8 \\
\hline No & 96 & 76.2 \\
\hline \multicolumn{3}{|l|}{ PORT } \\
\hline Yes & 55 & 43.7 \\
\hline No & 71 & 56.3 \\
\hline \multicolumn{3}{|c|}{ No. Cycles of ChT } \\
\hline$<4$ & 21 & 16.7 \\
\hline$\geq 4$ & 105 & 83.3 \\
\hline
\end{tabular}

Abbreviations: $\mathrm{SCLC}=$ small cell lung cancer; $\mathrm{KPS}=$ Karnofsky performance status; $\mathrm{P}$-stage $=$ pathologic stage; $\mathrm{LVI}=$ lymphovascular invasion; $\mathrm{PORT}=$ postoperative radiotherapy; $\mathrm{ChT}=$ chemotherapy.

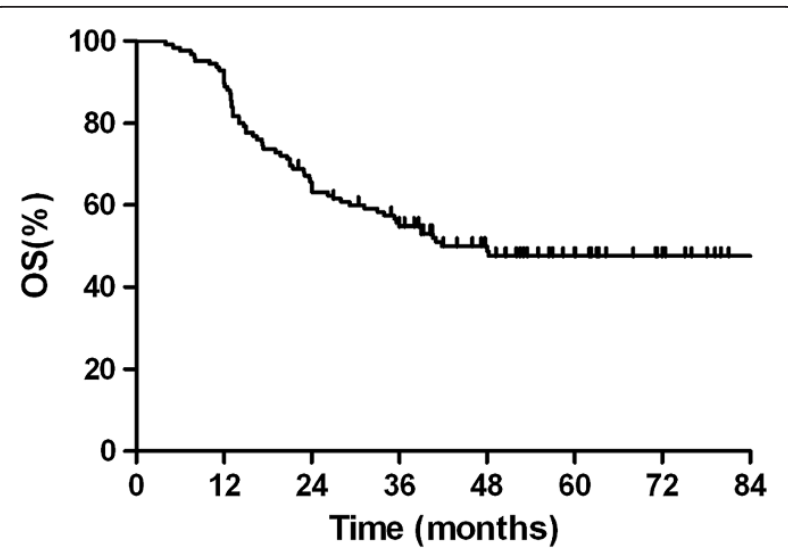

Figure 1 Overall survival curve for 126 patients with completely resected small cell lung cancer.
75 months, with a median time to development of BM of 10.9 months, which was calculated from the time of diagnosis. The incidence of BM was 9.4\% (3/32) in patients with p-stage I disease, $18.2 \%(6 / 33)$ in patients with pstage II disease, and 31.1\% (19/61) in patients with p-stage III disease.

The actuarial risk of developing BM in all patients at 1 year and 3 years was $13.8 \%$ and $23.0 \%$, respectively. The clinical and pathological factors evaluated to determine their prognostic value for the actuarial risk of developing BM are summarized in Table 3. The risk of developing BM was associated with pathologic stage. The actuarial risk of developing BM at 1 year and 3 years was $3.1 \%$ and $9.7 \%$, respectively, in patients with p-stage I disease; $15.4 \%$ and $18.5 \%$, respectively, in patients with p-stage II disease; and $18.8 \%$ and $35.4 \%$, respectively, in patients with $\mathrm{p}$-stage III disease $(p=0.013$, Figure 4$)$. Lymphovascular invasion (LVI) was also associated with $\mathrm{BM}$. The risk of developing $\mathrm{BM}$ at 1 year and 3 years in patients with LVI were $30.8 \%$ and $39.9 \%$, respectively, which is significantly higher compared with $9.8 \%$ and $17.5 \%$ respectively in patients without LVI $(p=0.003$; Figure 5).

Multivariate analysis indicated that pathologic stage $(\mathrm{HR}=2.013, p=0.017)$ and LVI $(\mathrm{HR}=1.924, p=0.039)$ were independent factors associated with increased risk of developing BM. Based on the results of the multivariate analysis, we analyzed the effect of these two independent high-risk factors affecting the incidence of BM. In patients with p-stage II disease and LVI $(n=11)$, the 1 -year and 3-year actuarial risk of developing BM was $29.3 \%$ and $29.3 \%$, respectively. In patients with p-stage II disease and no LVI $(\mathrm{n}=22)$, the 1-year and 3-year actuarial risk of developing BM was $9.1 \%$ and $13.6 \%$, respectively. In patients with p-stage III disease and LVI $(\mathrm{n}=17)$, the 1-year and 3-year actuarial risk of developing $\mathrm{BM}$ was $35.3 \%$ and $52.1 \%$, respectively. In patients with p-stage III disease and no LVI $(\mathrm{n}=44)$, the 1 -year and 3-year actuarial risk of developing BM was $12.2 \%$ and $27.5 \%$, respectively. The differences among the groups were statistically significant $(p=0.015)$. We did not analyze patients with p-stage I disease because only two patients with p-stage I disease had LVI.

\section{Discussion}

Chemotherapy combined with TRT is the standard treatment for the management of limited-stage (LS) SCLC. Nevertheless, the role of surgery as a part of multimodality treatment remains controversial. The NCCN guidelines recommend lobectomy and mediastinal lymph node dissection followed by ChT only for patients who are classified with clinical stage T1-2 N0 disease and who have negative pathological mediastinal staging after mediastinoscopy [10]. However, if the neoplasm was peripherally 
Table 2 Univariate and multivariate analysis of the effect of prognostic factors on OS in patients with resectable SCLC

\begin{tabular}{|c|c|c|c|c|c|c|c|}
\hline \multirow[b]{2}{*}{ Factors } & \multicolumn{4}{|c|}{ Univariate analysis } & \multicolumn{3}{|c|}{ Multivariate analysis } \\
\hline & $\begin{array}{c}2 y-O S \\
\%\end{array}$ & $\begin{array}{c}5 y-O S \\
\%\end{array}$ & $x^{2}$ & $p$ & HR & $95 \% \mathrm{Cl}$ & $p$ \\
\hline \multicolumn{8}{|l|}{ Gender } \\
\hline Male & 63.0 & 48.4 & & & & & \\
\hline Female & 64.0 & 43.6 & 0.015 & 0.901 & & & \\
\hline \multicolumn{8}{|c|}{ Age, years } \\
\hline$<65$ & 64.8 & 53.3 & & & & & \\
\hline$\geq 65$ & 58.9 & 32.2 & 3.079 & 0.079 & 1.798 & $1.027 \sim 3.148$ & 0.040 \\
\hline \multicolumn{8}{|c|}{ KPS score } \\
\hline$\geq 80$ & 71.5 & 56.9 & & & & & \\
\hline$<80$ & 61.5 & 42.3 & 3.487 & 0.062 & 1.149 & $0.631 \sim 2.092$ & 0.649 \\
\hline \multicolumn{8}{|c|}{ Smoking status } \\
\hline Yes & 62.1 & 52.0 & & & & & \\
\hline No & 64.7 & 42.3 & 0.284 & 0.594 & & & \\
\hline \multicolumn{8}{|l|}{ P-stage } \\
\hline । & 87.1 & 74.4 & & & & & \\
\hline$\|$ & 78.6 & 61.7 & & & & & \\
\hline III & 42.6 & 26.6 & 28.70 & 0.001 & 2.093 & $1.399 \sim 3.132$ & 0.001 \\
\hline \multicolumn{8}{|l|}{ LVI } \\
\hline Yes & 48.6 & 34.1 & & & & & \\
\hline No & 67.6 & 51.8 & 3.358 & 0.067 & 0.935 & $0.507 \sim 1.723$ & 0.829 \\
\hline \multicolumn{8}{|l|}{ PORT } \\
\hline Yes & 64.7 & 43.6 & & & & & \\
\hline No & 63.0 & 48.2 & 0.028 & 0.866 & & & \\
\hline \multicolumn{8}{|c|}{ Cycle of ChT } \\
\hline$<4$ & 61.9 & 57.1 & & & & & \\
\hline$\geq 4$ & 63.5 & 46.0 & 0.221 & 0.638 & & & \\
\hline \multicolumn{8}{|c|}{ Brain metastasis } \\
\hline Yes & 42.9 & 15.5 & & & & & \\
\hline No & 69.0 & 56.2 & 14.65 & 0.001 & 2.092 & $1.049 \sim 4.170$ & 0.031 \\
\hline
\end{tabular}

Abbreviations: $\mathrm{OS}=$ overall survival; $\mathrm{SCLC}=$ small cell lung cancer; $2 \mathrm{y}-\mathrm{OS}=$ overall survival rate at 2 years; $5 \mathrm{y}$-OS = overall survival rate at 5 years; $\mathrm{HR}=$ hazard ratio; $\mathrm{Cl}=$ confidence interval KPS = Karnofsky performance status; $\mathrm{P}$-stage = pathologic stage; $\mathrm{LVI}=$ lymphovascular invasion; $\mathrm{PORT}=$ postoperative radiotherapy; $\mathrm{ChT}=$ chemotherapy.

located and clinically diagnosed as malignant by experienced radiologists, and the result of transthoracic needle biopsy or bronchoscopy-based biopsy was negative, then surgery was still performed. In addition, surgery occasionally was performed at the discretion of the surgeons and/ or the patients' preference.

A favorable role for surgery in LS-SCLC treatment was alluded to in a Medical Research Council study [11]. However, in this clinical trial, only 34 of the 71 patients $(48 \%)$ scheduled to undergo surgery actually underwent surgery. Not surprisingly, surgery was not found to improve OS in this trial. A randomized Lung Cancer Study Group study reached a similar conclusion [12]. However, patients with T1N0 disease were excluded from this trial, and thus possibly explained the low survival of patients with early stage SCLC. The role of surgery was reevaluated after the recent introduction of the TNM staging system. A matched-pair analysis comparing 67 patients who underwent surgery followed by adjuvant ChT and 67 patients who received conventional non-surgical management revealed a 5 -year OS of $27 \%$ for the surgical group and $4 \%$ for the matched non-surgical cohort. Subset analysis confirmed significantly longer survival following surgery for T1-2 and N0-1 categories [13]. Several trials have demonstrated that surgery with adjuvant ChT results in a favorable survival rate for $\mathrm{p}$-stage I-III disease with a 5 -year OS of $31 \%-71 \%$ for patients with p-stage I disease [14-18]. The data from the Surveillance, Epidemiology, and End Results registry in 2010 was used to analyze the role of surgery in patients with localized disease 


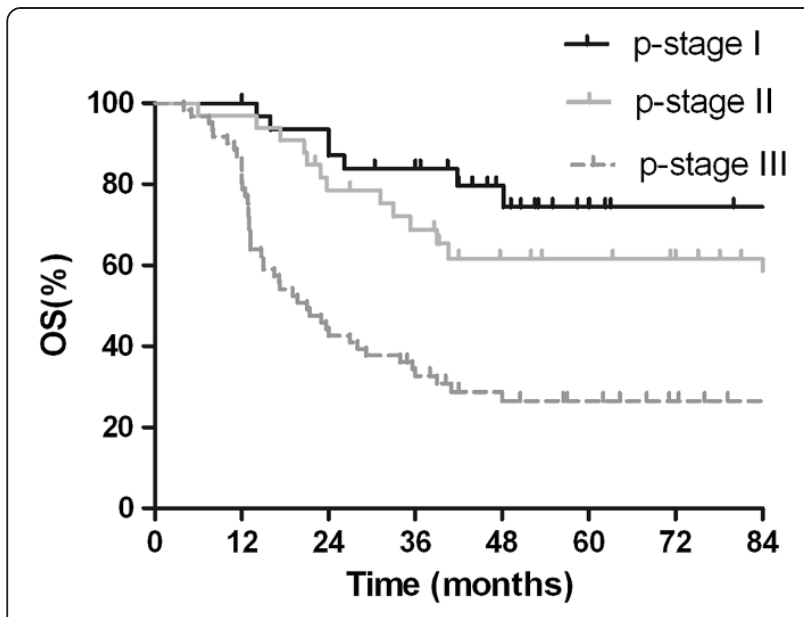

Figure 2 Comparison of overall survival of patients with surgically resected small cell lung cancer by pathologic stage.

(T1-T2Nx-N0) or regional disease (T3-T4Nx-N0). Of the 14,179 patients identified, 863 underwent surgical resection. Surgery was associated with improved survival for both localized disease and regional disease. The 5-year OS for patients who received surgery for localized disease was $44.8 \%$ compared to an OS of just $13.7 \%$ for the non-surgery group $(p<0.001)$. In addition, the 5 -year OS for patients with regional disease was $26.3 \%$ compared to an OS of $9.3 \%$ for the non-surgery group $(p<0.001)$. Furthermore, the OS for patients with lymph node involvement was also improved in the surgery group [19]. Our study demonstrates that the 5-year OS of patients with completely resected SCLC was $47.8 \%$, while the 5-year survival rates for p-stage $\mathrm{I}$, p-stage II, and p-stage III disease were $74.4 \%, 61.7 \%$, and $26.6 \%$, respectively, which are similar to the rates reported by others.

Additionally, in this series, most patients with lymph node metastasis were conducted with postoperative radiotherapy

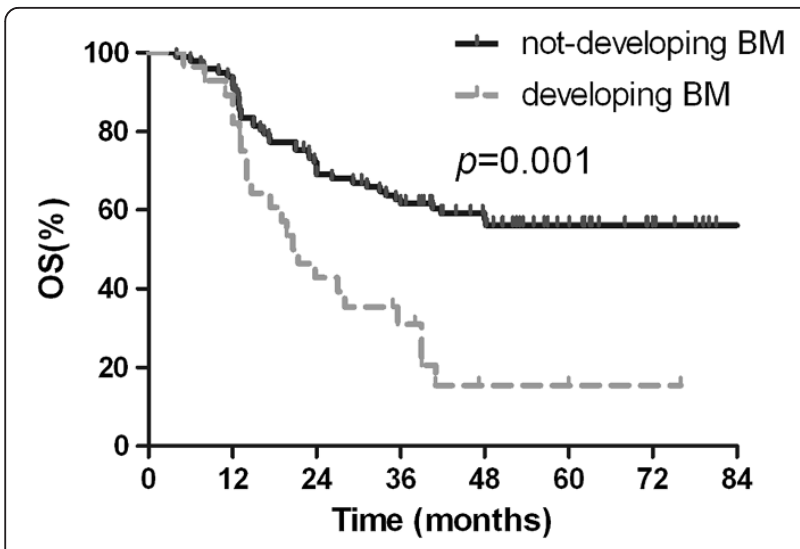

Figure 3 Comparison of overall survival between patients based on development of brain metastases.
Table 3 Factors associated with actuarial risk of developing BM for patients with resectable SCLC

\begin{tabular}{|c|c|c|c|c|c|c|c|}
\hline \multirow{2}{*}{ Factors } & \multicolumn{4}{|c|}{ Univariate analysis } & \multicolumn{3}{|c|}{ Multivariate analysis } \\
\hline & $1 y$ & $3 y$ & $3 y$ & $p$ & HR & $95 \% \mathrm{Cl}$ & $p$ \\
\hline \multicolumn{8}{|l|}{ Gender } \\
\hline Male & 14.3 & 23.0 & & & & & \\
\hline Female & 12.0 & 23.6 & 0.04 & 0.906 & & & \\
\hline \multicolumn{8}{|c|}{ Age, years } \\
\hline$<65$ & 14.5 & 22.4 & & & & & \\
\hline$\geq 65$ & 12.0 & 26.3 & 0.063 & 0.802 & & & \\
\hline \multicolumn{8}{|l|}{ KPS score } \\
\hline$\geq 80$ & 10.6 & 17.3 & & & & & \\
\hline$<80$ & 16.0 & 31.5 & 1.207 & 0.272 & & & \\
\hline \multicolumn{8}{|c|}{ Smoking status } \\
\hline Positive & 15.9 & 24.7 & & & & & \\
\hline Negative & 11.2 & 20.9 & 0.341 & 0.559 & & & \\
\hline \multicolumn{8}{|l|}{ P-stage } \\
\hline । & 3.1 & 9.7 & & & & & \\
\hline$\|$ & 15.4 & 18.5 & & & & & \\
\hline III & 18.8 & 35.4 & 8.621 & 0.013 & 2.013 & $1.135 \sim 3.569$ & 0.017 \\
\hline \multicolumn{8}{|l|}{ LVI } \\
\hline Yes & 30.8 & 39.9 & & & & & \\
\hline No & 9.8 & 17.5 & 8.943 & 0.003 & 1.924 & $1.002 \sim 3.291$ & 0.039 \\
\hline \multicolumn{8}{|l|}{ PORT } \\
\hline Yes & 17.6 & 33.5 & & & & & \\
\hline No & 13.2 & 21.3 & 3.351 & 0.067 & 0.825 & $0.329 \sim 2.064$ & 0.680 \\
\hline \multicolumn{8}{|c|}{ Cycle of ChT } \\
\hline$<4$ & 10.0 & 17.5 & & & & & \\
\hline$\geq 4$ & 14.5 & 24.2 & 0.240 & 0.624 & & & \\
\hline
\end{tabular}

Abbreviations: SCLC $=$ small cell lung cancer; $1 \mathrm{y}=$ actuarial risk of developing $B M$ at 1 year; $3 y=$ actuarial risk of developing $B M$ at 3 years; $H R=$ hazard ratio; $\mathrm{Cl}=$ confidence interval; $\mathrm{KPS}=$ Karnofsky performance status; $\mathrm{P}$-stage = pathologic stage; LVI = lymphovascular invasion; PORT = postoperative radiotherapy; $\mathrm{ChT}=$ chemotherapy.

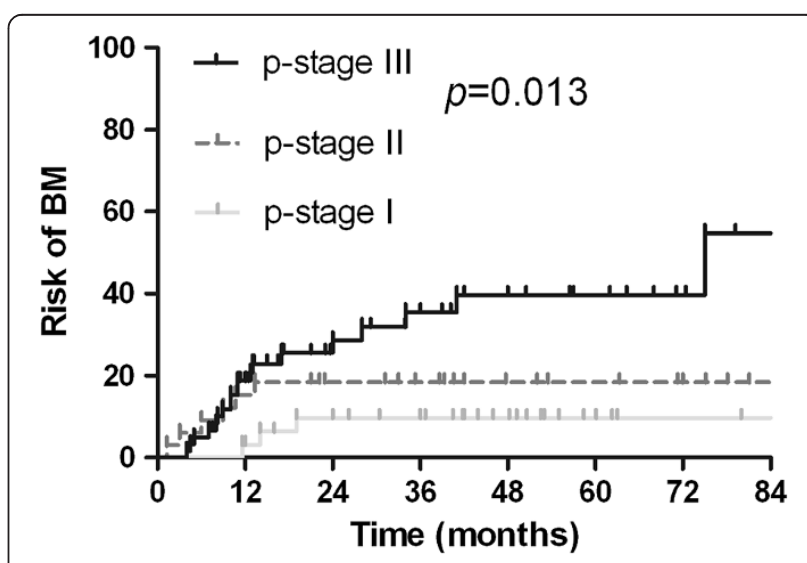

Figure 4 The actuarial risk of developing brain metastases in patients with different pathologic stage of completely resected SCLC. 


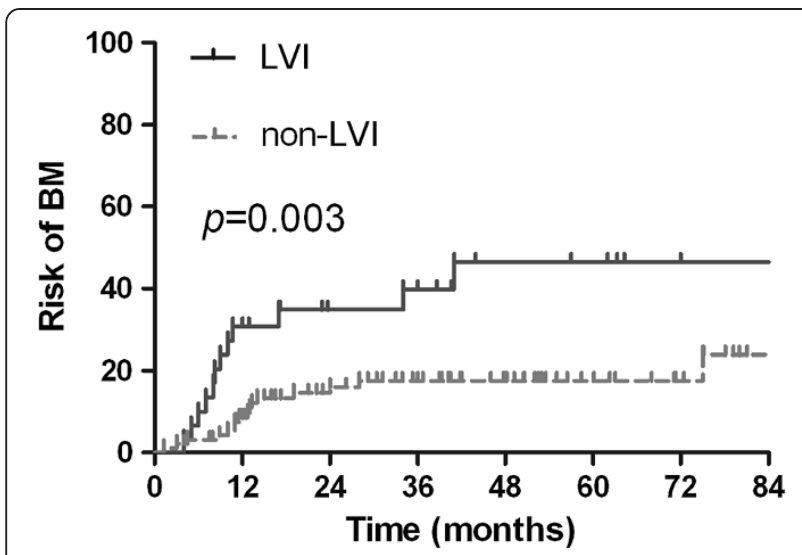

Figure $\mathbf{5}$ The actuarial risk of developing brain metastases based on the presence or absence of lymphovascular invasion.

(PORT), which could improve the local control and give survival benefit to the subgroup.

The positive role of PCI in patients with limited SCLC and extensive SCLC who achieve a complete response (CR) to ChT was established in 1999 by a meta-analysis that included data from seven randomized prospective studies comparing PCI with no PCI after a CR [6]. The 3 -year survival rate was $20.7 \%$ for patients who received PCI compared with $15.3 \%$ for those who did not receive PCI $(p=0.01)$. The disease-free survival of patients who received PCI was also improved. The role of PCI on SCLC was established on the basis of the two-stage system and the treatment modality of ChT and/or TRT. However, the use of PCI after combined-modality treatment with surgery for resectable LS-SCLC has not been investigated sufficiently. The analysis of surgical SCLC could provide evidence regarding the value of PCI since these specimens permit accurate pathological diagnosis and TNM staging. As far as we are aware, only four studies have evaluated the frequency of BM after surgery for LS-SCLC. In the study conducted by Gong et al., the frequency of $\mathrm{BM}$ in patients with p-stage I, II, and III diseases were $6.25 \%(2 / 32), 28.2 \%(11 / 39)$, and $29.1 \%$ (16/55), respectively [20]. One Japanese multiinstitutional phase II study (JCOG9101) has reported that the overall incidence of BM was 15\% (9/61) in patients with surgically resected SCLC, but only $11 \%$ $(4 / 35)$ in patients with p-stage I disease compared to $19.2 \%$ in patients with p-stage II or stage III disease [15]. Nakamura et al. analyzed the frequency of BM as a first relapse site and found a 7\% (2/30) BM rate for patients with p-stage I disease, $25 \%(3 / 12)$ for patients with p-stage II SCLC, and 27\% (7/26) for patients with p-stage III [21]. Ogawa et al. also reported the frequency of $\mathrm{BM}$, but only 28 patients were included in the study [22]. The combined results from these four studies revealed that $\mathrm{BM}$ as the first complication developed in only $7.2 \%(8 / 111)$ of patients with p-stage I SCLC, while BM developed in $30.3 \%$ (20/66) of patients with p-stage II and $24.5 \%$ (26/106) of patients with p-stage III.

In our study, we found that the incidence of BM was only $9.4 \%(3 / 32)$ in patients with p-stage I disease. Similarly, the results of the four studies discussed above also suggest that PCI maybe not necessary for patients with p-stage I SCLC. Only one retrospective study has suggested a survival benefit is conferred by the use of PCI in surgically managed patients with p-stage I and II disease. In this study, only 39 cases with resected pT1-2 N0-1 M0 LS-SCLC were included, BM-free survival $(p=0.01)$ and OS $(p=0.01)$ were improved in patients who received PCI [23]. To summarize, the incidence of BM in patients with p-stage I SCLC was less than $10 \%$ and the evidence of survival benefit of PCI for this subgroup patients was in shortage, so PCI should be considered cautiously for surgically managed patients with p-stage I SCLC and deserve further study.

\section{Conclusion}

Patients with completely resected p-stage II/III SCLC and LVI are at the highest risk for BM.

\section{Competing interests}

The authors declare that they have no competing interests.

\section{Authors' contributions}

$\mathrm{HZ}$ and $\mathrm{YB}$ drafted the manuscript. $\mathrm{HZ}, \mathrm{YB}, \mathrm{AH}, \mathrm{ML}$, JL, and $\mathrm{FS}$ participated in the coordination of the study and contributed to analyze the data. LK and JY conceived of the study, participated in its design, and contributed to analyze the data. All authors made substantial contributions to the acquisition of data and approved the final manuscript.

\section{Acknowledgements}

This study was supported by Grant No. ZR2011HM089 from the Natural Science Foundation of Shandong Province to Li Kong.

\section{Author details}

'Department of Radiation Oncology, Shandong Cancer Hospital and Institute, Shandong University, Jiyan Rd. 440, Jinan 250117, Shandong Province, China. ${ }^{2}$ Department of Radiology, the Airforce General Hospital of Chinese People's Liberation Army, Beijing, China. ${ }^{3}$ Department of Thoracic Surgery, Shandong Cancer Hospital and Institute, Jinan, Shandong Province, China.

Received: 10 June 2014 Accepted: 16 September 2014

Published: 20 September 2014

\section{References}

1. Govindan R, Page N, Morgensztern D, Read W, Tierney R, Vlahiotis A, Spitznagel EL, Piccirillo J: Changing epidemiology of small-cell lung cancer in the United States over the last 30 years: analysis of the surveillance, epidemiologic, and end results database. J Clin Oncol 2006, 24:4539-4544.

2. Bayman NA, Sheikh H, Kularatne B, Lorigan P, Blackhall F, Thatcher N, Faivre-Finn C: Radiotherapy for small-cell lung cancer-Where are we heading? Lung Cancer 2009, 63:307-314.

3. Socha J, Kepka L: Prophylactic cranial irradiation for small-cell lung cancer: how, when and for whom? Expert Rev Anticancer Ther 2012, 12:505-517.

4. Seute T, Leffers $P$, ten Velde GP, Twijnstra A: Neurologic disorders in 432 consecutive patients with small cell lung carcinoma. Cancer 2004, 100:801-806. 
5. Komaki R, Cox JD, Whitson W: Risk of brain metastasis from small carcinoma of the lung related to length of survival and prophylactic irradiation. Cancer 1981, 65:811-814.

6. Auperin A, Arriagada R, Pignon JP, Le Pechoux C, Gregor A, Stephens RJ, Kristjansen PE, Johnson BE, Ueoka H, Wagner H, Aisner J: Prophylactic cranial irradiation for patients with small-cell lung cancer in complete remission: a meta-analysis of individual data from 987 patients. $N$ Engl $J$ Med 1999, 341:476-484.

7. Patel S, Macdonald OK, Suntharalingam M: Evaluation of the use of prophylactic cranial irradiation in small cell lung cancer. Cancer 2009, 115:842-850.

8. Slotman B, Faivre-Finn C, Kramer G, Rankin E, Snee M, Hatton M, Postmus P, Collette L, Musat E, Senan S, EORTC Radiation Oncology Group and Lung Cancer Group: Prophylactic cranial irradiation in extensive small-cell lung cancer. N Engl J Med 2007, 357:664-672.

9. Schild SE, Foster NR, Meyers JP, Ross HJ, Stella PJ, Garces Yl, Olivier KR, Molina JR, Past LR, Adjei AA, North Central Cancer Treatment Group: Prophylactic cranial irradiation in small-cell lung cancer: Findings from a North Central Cancer Treatment Group Pooled Analysis. Ann Oncol 2012, 23:2919-2924

10. National Comprehensive Cancer Network (NCCN) (2011) NCCN Practice Guidelines in Oncology, Version 1: Available at http://www.nccn.org/ professionals/physician_gls/PDF/sclc.pdf (accessed 14 January 2011).

11. Fox W, Scadding JG: Medical Research Council comparative trial of surgery and radiotherapy for primary treatment of small-celled or oat-celled carcinoma of bronchus. Ten-year follow-up. Lancet 1973, 2:63-65.

12. Lad T, Piantadosi S, Thomas P: A prospective randomized trial to determine the benefit of surgical resection of residual disease following response of small cell lung cancer to combination chemotherapy. Chest 1994, 106:320-323.

13. Badzio A, Kurowski K, Karnicka-Mlodkowska H, Jassem J: A retrospective comparative study of surgery followed by chemotherapy vs nonsurgical management in limited-disease small cell lung cancer. Eur J Cardiothorac Surg 2004, 26:183-188.

14. Brock MV, Hooker CM, Syphard JE, Westra W, Xu L, Alberg AJ, Mason D, Baylin SB, Herman JG, Yung RC, Brahmer J, Rudin CM, Ettinger DS, Yang SC: Surgical resection of limited disease small cell lung cancer in the new era of platinum chemotherapy: its time has come. J Thorac Cardiovasc Surg 2005, 129:64-72.

15. Tsuchiya R, Suzuki K, Ichinose $Y$, Watanabe $Y$, Yasumitsu T, Ishizuka N, Kato $\mathrm{H}$ : Phase II trial of postoperative adjuvant cisplatin and etoposide in patients with completely resected stage I-IIIA small-cell lung cancer: the Japan Clinical Oncology Lung Cancer Study Group Trial (JCOG9101). J Thorac Cardiovasc Surg 2005, 129:977-983.

16. Yu JB, Decker RH, Detterbeck FC, Wilson LD: Surveillance epidemiology and end results evaluation of the role of surgery for stage I small cell lung cancer. J Thorac Oncol 2010, 5:215-219.

17. de Antonio DG, Alfageme F, Gamez P, Cordoba M, Varela A: Results of surgery in small cell carcinoma of the lung. Lung Cancer 2006, 52:299-304

18. Zhu H, Zhou ZM, Xue Q, Zhang X, He J, Wang L: Treatment modality selection and prognosis of early stage small cell cancer: retrospective analysis from a single cancer institute. Eur J Cancer Care (Engl) 2013, 22:789-796.

19. Schreiber D, Rineer J, Weedon J, Vongtama D, Wortham A, Kim A, Han P, Choi K, Rotman M: Survival outcomes with the use of surgery in limited-stage small cell lung cancer: should its role be re-evaluated? Cancer 2010, 116:1350-1357.

20. Gong L, Wang QI, Zhao L, Yuan Z, Li R, Wang P: Factors affecting the risk of brain metastasis in small cell lung cancer with surgery: is prophylactic cranial irradiation necessary for stage I-III disease? Int J Radiat Oncol Biol Phys 2013, 85:196-200.

21. Nakamura $H$, Kato $Y$, Kato $H$ : Outcome of surgery for small-cell lung cancer-response to induction chemotherapy predicts survival. Thorac Cardiovasc Surg 2004, 52:206-210.
22. Ogawa $S$, Horio $Y$, Yatabe $Y$, Fukui T, Ito $S$, Hasegawa $Y$, Mitsudomi T, Hida T: Patterns of recurrence and outcome in patients with surgically resected small cell lung cancer. Int J Clin Oncol 2012, 17:218-224.

23. Bischof M, Debus J, Herfarth K, Muley T, Kappes J, Storz K, Hoffmann H: Surgery and chemotherapy for small-cell lung cancer in stages I-II with or without radiotherapy. Strahlenther Onkol 2007, 183:679-684.

doi:10.1186/1748-717X-9-216

Cite this article as: Zhu et al:: Risk factors for brain metastases in completely resected small cell lung cancer: a retrospective study to identify patients most likely to benefit from prophylactic cranial irradiation. Radiation Oncology 2014 9:216.

\section{Submit your next manuscript to BioMed Central and take full advantage of:}

- Convenient online submission

- Thorough peer review

- No space constraints or color figure charges

- Immediate publication on acceptance

- Inclusion in PubMed, CAS, Scopus and Google Scholar

- Research which is freely available for redistribution 